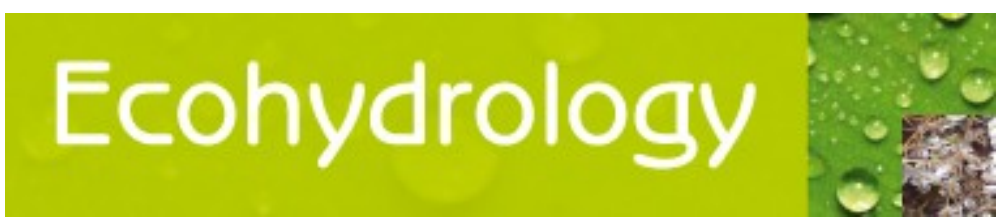

\title{
Structural and functional responses of macroinvertebrate assemblages to long-term flow variability at perennial and non-perennial sites
}

\begin{tabular}{|r|l|}
\hline Journal: & Ecohydrology \\
\hline Manuscript ID & ECO-19-0020.R1 \\
\hline Wiley - Manuscript type: & Research Article \\
\hline Author: & n/a \\
\hline Complete List of Authors: & $\begin{array}{l}\text { Mathers, Kate; Eawag Oberflachengewasser, } \\
\text { Stubbington, Rachel; Nottingham Trent University School of Science and } \\
\text { Technology, ; Nottingham Trent University } \\
\text { Westwood, Chris; ERA-UK, hydroecology } \\
\text { Leeming, David; DJL Ecologists Ltd } \\
\text { England, Judy; Environment Agency, }\end{array}$ \\
\hline Keywords: & $\begin{array}{l}\text { functional traits, instream habitat, intermittent streams, stability, } \\
\text { heterogeneity, flow permanence, hydrology }\end{array}$ \\
\hline &
\end{tabular}

\section{SCHOLARONE \\ Manuscripts}


1 Structural and functional responses of macroinvertebrate assemblages to long-term

2 flow variability at perennial and non-perennial sites

3 Kate L. Mathers ${ }^{1-2}$, Rachel Stubbington ${ }^{3}$, David Leeming ${ }^{4}$, Christian Westwood ${ }^{5}$,

4 Judy England 6

5 1. Eawag, Department of Surface Waters Research and Management, 6047

$6 \quad$ Kastanienbaum, Switzerland.

7 2. School of Animal, Rural and Environmental Sciences, Nottingham Trent

$8 \quad$ University, Nottingham, UK. NG25 0QF.

9 3. School of Science and Technology, Nottingham Trent University, Nottingham, $10 \quad$ UK. NG11 8NS.

11 4. DJL Ecologists Ltd., Old Bells Farm, The Street, Billingford, Dereham, Norfolk, $12 \quad$ UK. NR20 4RF.

13 5. Environmental Research Associates, Exeter, UK

14 6. Environment Agency, Red Kite House, Howbery Park, Crowmarsh Gifford, 15 Wallingford, UK. OX10 8BD.

\section{Author for Correspondence}

17 Kate Mathers

18 Eawag,

19 Department of Surface Waters Research and Management, 206047 Kastanienbaum,

21 Switzerland.

22 Email:- kate.mathers@eawag.ch

23 Running headline: Macroinvertebrate responses to flow variability

24 Key-words: functional traits, instream habitat, intermittent streams, stability, 25 heterogeneity, flow permanence, hydrology. 


\section{Abstract}

27 Temporary streams constitute a significant proportion of rivers globally and are common in wet, cool, temperate regions. These heterogeneous ecosystems harbour high biodiversity associated with the dynamic turnover of taxa. Despite flow

30 permanence being widely recognised as an important environmental control, few 31 studies have characterised biotic responses to long-term hydrological variability in 32 temporary streams. We examined taxonomic and functional macroinvertebrate 33 communities of perennial and non-perennial river reaches over a 26-year period.

34 Flow permanence resulted in spatial variation in taxonomic and functional 35 macroinvertebrate communities. Non-perennial river reaches, which were 36 characterised by dynamic habitat provision (lotic, lentic and dry states) over the 37 study period, supported more heterogeneous communities than perennial river reaches. Hydrological variables, in particular wetted width, water depth and zero-flow states, were instrumental in structuring taxonomic and functional communities,

40 although the importance of substrate conditions increased in autumn. Hydrological 41 conditions resulted in separation of perennial and non-perennial taxonomic 42 communities regardless of season, whereas functional communities differed only in 43 spring. Our results emphasise that understanding of community responses to 44 hydrological variability is enhanced by analyses that concurrently explore taxonomic 45 and functional responses to long-term intra- and inter-annual hydrological variability.

46 Moreover functional responses represents a robust method to test ecological 47 responses to hydrological drivers. Further research that builds on our work is needed 48 to inform the protection of both perennial and non-perennial streams as they adapt to 49 ongoing environmental change. 


\section{Introduction}

52 Hydrological variability and in particular flow permanence (Poff \& Ward, 1989) are primary determinants of aquatic community composition in lotic ecosystems (Smith \& Wood, 2002; Datry et al., 2014a). Non-perennial streams are defined by flow cessation, often experience partial or complete surface drying, and are characterised by high temporal and spatial variability (Leigh et al., 2015; Datry, Larned, \& Tockner, 2014b; Cid et al., 2017). The frequency, magnitude, duration and predictability of transitions between lotic, lentic and dry states influence the diversity and connectivity of habitat patches and, in turn, biotic responses (Bogan \& Lytle, 2007; Leigh \& Datry, 2017). As such, non-perennial reaches often support high biodiversity as communities vary in space and time in response to changing habitat availability (Bogan, Boersma, \& Lytle, 2013; Rolls, Heino, \& Chessman, 2016; Tonkin et al., 2017).

Historically, most research considering macroinvertebrate responses to flow permanence has focused on taxonomic changes. As discharge declines, flowing habitats are typically lost and rivers become dominated by connected pools inhabited

67 by both lotic refugees and lentic colonists (Hill \& Milner, 2018). Over time, pools 68 become isolated and community composition continues to diverge from the lotic 69 community as lentic colonists become increasingly dominant (Bonada, Rieradevall, 70 Prat, \& Resh, 2006). Flow resumption allows rapid recolonisation by resistant and 71 resilient lotic species (Rolls et al., 2016; Vander Vorste, Corti, Sagouis, \& Datry, 72 2016). Communities within sites with contrasting flow permanence regimes may 73 therefore converge as flowing phase durations increase (Wood, Gunn, Smith, \& 74 Abas-Kutty, 2005; Vander Vorste et al., 2016). However, studies of biotic responses 75 to flow permanence are typically short-term (months to years), leaving long-term 
76

77

78

79

80

81

82

83

84

85

86

87

88

89

90

91

92

93

94

95

96

97

98

99

100

(decadal) patterns poorly characterised (but see Bêche, Connors, Resh, \&

Merenlender, 2009; Stubbington, Wood, \& Boulton, 2009; Chessman, 2015; Leigh \&

Datry, 2017; Wilding et al., 2018).

In addition to taxonomic responses, biological traits based on life history, behaviour morphology and physiology may be more informative when investigating community responses to hydrological variability and flow permanence (Menezes, Baird, \&

Soares, 2010; Schriever et al., 2015). Understanding life-history traits (such as body size, morphology, lifecycle) associated with the habitat template via functional trait analysis has been cited as strong basis for the theoretical development of ecological indicators (Statzner \& Bêche, 2010). Macroinvertebrates within non-perennial streams may exhibit $r$-selected traits such as high dispersal, short life histories, rapid growth and opportunistic feeding modalities that promote resilience to drying and enable persistence in dynamic environments (Williams, 1996; García-Roger et al., 2013; Giam et al., 2017). Taxa may also possess traits promoting resistance to drying, such as desiccation-tolerant forms or respiration systems which permit air breathing (Leigh et al., 2016; Datry et al., 2017a). The prevalence of taxa possessing resistance traits may result in functional redundancy increasing with intermittence (García-Roger et al., 2013; Boersma, Bogan, Henrichs, \& Lytle, 2014). In turn, functional redundancy can stabilise community trait composition over time (Bêche, Mcelravy, \& Resh, 2006), potentially facilitating clearer discrimination between assemblages from sites with contrasting flow permanence compared to taxonomic approaches (Cid et al., 2016; García-Roger, 2017). Communities in reaches which dry infrequently or unpredictably may be decoupled from such adaptations, and may therefore exhibit stronger taxonomic and functional responses (Bêche et al., 2009; Chessman, 2015). 
101 Recognition of their extensive and increasing occurrence, biodiversity, and 102 ecosystem service provision has resulted in increased research examining temporary streams (Leigh et al., 2015; Datry et al., 2018). Despite this increase, most ecological studies are from Mediterranean and dryland climates (e.g. Bonada, 105 Rieradevall, \& Prat, 2007; Bogan et al., 2015; Cid et al., 2016; Leigh et al., 2016), 106 whereas research in cooler, wetter temperate climates remains restricted to a few 107 well-studied rivers including groundwater-dominated streams (Wood \& Petts, 1999; 108 Hill \& Milner, 2017; White et al., 2018). Such systems support high biodiversity 109 including rare species but are particularly sensitive to hydrological alterations, which 110 may manifest instream as reduced discharge in perennial reaches, as flow cessation 111 or drying in near-perennial reaches, and as prolonged ponded or dry states in nonperennial reaches. This spatial variability makes groundwater-dominated streams useful systems in which to examine ecological responses to hydrological variability 114 (Wright, 1992).

115 This study examined taxonomic and functional macroinvertebrate assemblage 116 responses to antecedent hydrological variability (including flow cessation and drying 117 events) at sites with contrasting flow permanence regimes in a UK groundwater118 dominated stream. We analysed a long-term dataset consisting of macroinvertebrate 119 samples and continuous, site-specific hydrological measurements. Hydrological data 120 were supplemented by observations of flow states aiding discrimination between 121 lentic conditions and streambed drying events. The following research questions 122 were addressed:

123 (i) Do perennial and non-perennial river reaches support distinct taxonomic 124 and functional macroinvertebrate assemblages? 
125

126

127

128

129

130

131

132

133

134

135

136

137

138

139

140

141 Six sampling sites (1-6 from upstream to downstream) with contrasting flow

142 permanence were examined during the 26-year study period (1990-2016; Table 1;

143 Figure 1). For the purposes of this study, sites were categorised as 'non-perennial'

144 being those that dry regularly (sites 1, 3 and 4), or 'perennial' being those that never

145 cease to flow or maintain flow except during extreme drought events (sites 2, 5 and

146

6.) Table 1 summarises the physical characteristics of each site and the flow

147 permanence regime according to two hydrological metrics: the six-month

148 predictability of dry periods (Sd6; which ranges from 0 - no predictability to 1 - total

149

(ii) Does heterogeneity of taxonomic and functional macroinvertebrate assemblages differ between perennial and non-perennial river reaches?

(iii) Which environmental parameters are influential in structuring the composition of taxonomic and functional macroinvertebrate assemblages in perennial and non-perennial river reaches?

\section{Methods}

\subsection{Study sites}

The River Misbourne is a small chalk stream in southern England which flows for approximately $27 \mathrm{~km}$ to its confluence with the River Colne (Figure 1). Land use within the $94.8 \mathrm{~km}^{2}$ catchment is predominately arable (34.07\%) with some grassland (28.33\%), mixed woodland (21.50\%) and urban land cover (16.67\%); NRFA, 2017).

The Misbourne experiences predictable annual discharge variation and loses water from its upper reaches and the middle section upstream of Chalfont St. Peter (Figure 
150 Hydrological variability was evident within and among the six sampling sites during 151 the study period. Droughts occurred in England in 1997-1998, 2006-2007 and 2011152 2012, and wet phases in 2001 and 2014 (Marsh, Cole, \& Wilby, 2007; Marsh et al., 153 2013).

\section{$154 \quad 2.2$ Macroinvertebrate data}

155 Benthic macroinvertebrate samples were collected by the Environment Agency of 156 England using their standard sampling protocol for statutory monitoring purposes: a 157 3-minute kick sample (1-mm mesh size) encompassing all habitats in proportion to 158 their occurrence, followed by a 1-minute hand search (Murray-Bligh, 1999).

159 Sampling was conducted in spring (March - May) and autumn (September 160 November; UKTAG, 2014) and began between 1990 and 1998 (dependent on site) 161 and continued until 2016. For sites surveyed more than once in a single sampling 162 season, the most recent replicate was retained to ensure independence of samples, 163 leaving a total of 180 samples. Taxa were mainly identified to family level, except Hydracarina and Collembola, which were recorded as such. Due to the semiquantitative technique, abundance data were standardised into ordinal classes (1 = $1-9,2=10-32,3=33-99,4=100-332,5=333-999,6=\geq 1000$ individuals per

167 sample; Durance \& Ormerod, 2009; Mathers et al., 2016). 168

169 The functional composition of macroinvertebrate communities was characterised by 170 assigning taxa into 11 categories comprising 61 biological traits from the Tachet, 171 Bournaud, Richoux, \& Usseglio-Polatera (2010) database (Table S1). Traits were 172 assigned to genera based on a fuzzy-coding approach with scores ranging from zero 173 (indicating no affinity) to five (the strongest affinity based on available literature;

174 Chevene, Doléadec, \& Chessel, 1994). Because we worked at the family level, we 
175 averaged the affinities of all genera recorded within a family and these affinity scores

176 were rescaled as proportions for each category (sum=1) for each taxon (sensu

177 Gayraud et al., 2003). To produce a trait abundance matrix, taxon-trait categories

178 were multiplied by the ordinal abundances and subsequently scaled such that each

179 trait equalled one (Larsen \& Ormerod, 2010a; Descloux, Datry, \& Usseglio-Polatera, 180 2014; White et al., 2017a). Trait abundance and diversity can be achieved at the 181 family level (i.e.) regardless of spatial scales (Gayraud et al., 2003; García-Roger et 182 al., 2013). Chironomidae and taxa recorded at a coarser resolution than family level 183 were excluded, because these taxa are likely to include multiple representatives with 184 highly variable responses (Monk et al., 2012; Cañedo-Argüelles, Bogan, Lytle, \& 185 Prat, 2016) Of the 90 taxa recorded, 78 were assigned functional traits. Alpha 186 diversity of each sample was determined via taxa richness and the inverse

187 Simpson's diversity value (Oksanen et al., 2015), which accounts for the fixed 188 number of traits and the lack of independence between traits (Larsen \& Ormerod, 189 2010b; White et al., 2017b).

\section{$190 \quad 2.3$ Hydrological data}

191 Discharge has been gauged continuously in the lower Misbourne $\left(51^{\circ} 40^{\prime} \mathrm{N}, 00^{\circ} 39^{\prime}\right.$ 192 W) since 1985 and in the upper river (51 $\left.{ }^{\circ} 34^{\prime} \mathrm{N}, 00^{\circ} 29^{\prime} \mathrm{W}\right)$ since 1993 (Figure 1) with 193 additional spot discharge measurements taken along the river under varying flow 194 conditions (Figure 1). Table S2 shows the time periods and number of spot gauge 195 measurements used to establish flow relationships at each site. Daily mean 196 discharge data provided by the Environment Agency of England (available from 197 NRFA, 2017) and spot-gauging measurements closest to the biological monitoring 198 sites were used to generate site-specific discharge time series using linear 199 regressions (see Gordon, McMahon, Finlayson, Gippel, \& Nathan 2004). This 
200 approach provides sufficient representation of hydrological conditions at a site, gives 201 a good description of relative patterns but may lack precision for low flows (Malcolm 202 et al., 2012a), and has been used successfully in hydroecological assessments 203 (Gordon et al., 2004; Westwood et al., 2017). For sites 2-5, between one and four 204 linear regressions were constructed reflecting different hydrological periods 205 associated with discharge levels (Table S2). Figure 2 provides hydrographs for 206 typical perennial and non-perennial river reaches.

207

208 Using the derived daily mean discharge data, we calculated antecedent hydrological 209 metrics previously shown to be relevant when examining macroinvertebrate 210 response to flows (Dunbar et al. 2010a, 2010b). We divided the year into two periods 211 which we termed summer flows (April-September) and winter flows (October212 March). Each flow period for each site thus provides a series of blocks of discharge 213 data, each of 183 days for summer and 182/183 days for winter. For each block, two 214 statistics were calculated: the \% of zero-flow days for the previous year (\% of winter 215 zero-flow days - \% W1 zero-flow days; \% of summer zero-flow days - \% S1 zero216 flow days) and two characterising mean discharge (mean winter discharge - Mean 217 W1; mean summer discharge - Mean S1). In addition, mean discharge (Mean S2) 218 and \% of zero-flow days (\% S2 zero-flow days) were calculated for the summer 219 before S1, resulting in six hydrological statistics.

\section{$220 \quad 2.4$ Data analysis}

221 2.4.1 Macroinvertebrate responses in perennial and non-perennial river reaches

222 All analyses were conducted in R version 3.4.3 (R Development Core Team, 2017).

223 To assess whether alpha diversity varied in association with flow permanence 224 regime (perennial or non-perennial), season, site and the interaction of these factors, 
225 differences in alpha diversity were tested via a linear mixed-effects model using the

226 'Ime' function in the 'nlme' package (Pinheiro et al., 2016). Season, site and flow

227 permanence regime were fitted as fixed interacting effects and year as a random

228 effect to account for community compositions from individual sites being potentially

229 correlated over time. Significance values were obtained using Type II analysis of

230 variance (ANOVA) in the 'car' package (Fox \& Weisberg, 2011). Marginal ${ }^{2}$

231 (proportion of variance explained by the fixed effects alone) and conditional $\mathrm{r}^{2}$

232 (proportion of variance explained by the fixed and random effects) values were

233 extracted using the 'MuMIn' package (Bartoń, 2016).

234 Differences in community composition were explored as a function of the interactive 235 explanatory factors of site, flow permanence regime and season via a permutational 236 multivariate ANOVA (PERMANOVA) using the 'adonis' function in the 'vegan'

237 package (Oksanen et al., 2015). Indicator taxa and traits were identified for perennial 238 and non-perennial sites using the 'multipatt' function within the 'indicspecies' 239 package (De Cáceres \& Jansen, 2016). An indicator value of $>0.25$ was accepted as 240 ecologically relevant (Dufrêne \& Legendre, 1997), and all significant indicators with a

241 fidelity value of $<0.25$ removed to exclude rare taxa and traits (De Cáceres,

242 Legendre, Wiser, \& Brotons, 2012; Trivellone et al., 2014). Indicator values were 243 assigned based on global, spring and autumn datasets to assess variation between 244 seasons.

245 2.4.2 Heterogeneity in macroinvertebrate community composition in perennial and 246 non-perennial river reaches

247 To examine heterogeneity in macroinvertebrate community composition,

248 homogeneity of multivariate dispersions were calculated for functional and taxonomic 249 communities based on Bray-Curtis distances using the 'betadisper' function in 
250 'vegan'. Tests were run on flow permanence regime (perennial and non-perennial)

251 on global, spring and autumn datasets. Statistical differences in multivariate

252 dispersion between the flow permanence groups and within flow permanence regime

253 by season were tested using one-way ANOVA. Heterogeneity of all taxonomic and

254 functional samples (regardless of factors) were determined to establish overall

255 temporal variability of the two approaches and tested using ANOVA.

\section{2.4.3 Perennial and non-perennial macroinvertebrate community associations with}

257 environmental variables

258 Redundancy analyses (RDA) were performed using the 'ordistep' function in 'vegan'

259 to examine relationships between taxonomic / functional composition and 13

260 environmental parameters, specifically six hydrological metrics (described above),

261 five substrate characteristics assessed via visual estimates (\% boulders, cobbles,

262 pebbles, gravel, silt), and two mean wetted channel dimensions (width, depth;

263 Murray-Bligh, 1999). Prior to analysis, a Hellinger transformation was applied to the

264 taxonomic data. A stepwise (forward and backward) selection procedure using

265 permutational-based significance tests (999 permutations) was used to identify

266 factors that influenced assemblages, with only significant variables included in the

267 final model. Final variables were checked for collinearity using the 'vif function in the 268 'car' package to ensure that all 'variance inflation factors' were <3 (Zuur et al., 2010).

269 Analyses were conducted on spring and autumn datasets for taxonomic and

270 functional communities.

\section{3. Results}

2723.1 Macroinvertebrate responses in perennial and non-perennial river reaches

273 Taxa richness for the 26-year study period was higher at perennial sites (mean \pm SE $27434 \pm 0.56$, range 9-39) compared to non-perennial sites (18 \pm 0.81 , range 4-30) with 
27515 families being unique to perennial river reaches (most notably Odontoceridae and 276 Psychomyiidae). Functional diversity was higher at perennial sites (mean inverse 277 Simpson's diversity value $31 \pm 0.11)$ compared to non-perennial sites $(21 \pm 0.21)$.

278 Taxonomic richness and functional diversity varied as a function of flow permanence 279 regime and the interaction of flow permanence regime and site but not by the 280 individual influence of site and season or the interaction of any other factors (all $281 p>0.05$; Table 2).

282 Site explained the greatest amount of variation in taxonomic community composition, 283 whereas the interaction of site and flow permanence regime was the most influential 284 factor for functional community composition, as indicated by the greater $\mathrm{r}^{2}$ and $\mathrm{F}$ 285 values (Table 3). Both taxonomic and functional communities differed as a function 286 of site, season and flow permanence regime and the interaction of flow regime and 287 site (Table 3). There was no interaction between season and either site or flow 288 permanence regime.

289 Indicator analysis (Table 4) determined that non-perennial sites were characterised 290 by taxa with resistance forms including cocoons and housing against desiccation, 291 such as Lymnaeidae, the strongest indicator taxon. These sites also supported taxa 292 that temporarily attach to substrates and surface swimmers (e.g. Dytiscidae). The 293 family Lumbricidae was also a strong indicator of non-perennial sites. Perennial sites 294 supported large taxa ( $>8 \mathrm{~cm}$, e.g. Erpobdellidae), taxa with $<1$ brood per year, those 295 with parasitic and carnivorous feeding modes (e.g. Erpobdellidae, Glossiphoniidae), 296 and those permanently attached to substrates (e.g. Hydrobiidae). Indicator values 297 were generally higher for traits than for taxa and at perennial sites than non298 perennial sites (Table 4), and taxonomic indicator values were higher in spring 
299 compared to autumn (Tables S3 and S4). Indicators were generally comparable 300 between seasons with a few exceptions at non-perennial sites, notably Corixidae, 301 Hydroptilidae, Crangonyctidae in autumn and Lumbricidae in spring. Taxa with 302 passive aquatic dispersal, small body size $(>1-2 \mathrm{~cm}$ and $<0.25 \mathrm{~cm})$ and with adult 303 aquatic stage characterised autumn samples whilst spring supported taxa that 304 temporally attach to substrates or which have an aquatic nymph stage.

3053.2 Heterogeneity in macroinvertebrate community composition in perennial 306 and non-perennial river reaches

307 Taxonomic communities demonstrated greater temporal dispersion (mean distance 308 of all communities: 0.369$)$ than functional communities (0.084). Heterogeneity was 309 higher at non-perennial sites compared to perennial sites for taxonomic and 310 functional communities regardless of season (Table 5). Both taxonomic and 311 functional communities differed in heterogeneity between perennial and non312 perennial sites within the global and spring models, whereas only functional 313 communities differed in autumn (Table 6). Heterogeneity within perennial or non314 perennial groups was comparable between seasons (all $p>0.05$ ), but was generally 315 lower in autumn at non-perennial sites, in both taxonomic and functional community 316 composition.

\section{3.3 Perennial and non-perennial macroinvertebrate community associations} 318 with environment variables

319 All RDA models were highly significant (all $p=0.001)$, with functional communities 320 demonstrating a stronger association with the measured environmental parameters 321 and the models accounting for greater variance on the first two axes, especially in 322 spring (range 27.77-18.92\%; Table S5). In all instances, hydrological metrics and 
323 wetted channel characteristics influenced functional and taxonomic community

324 composition. Width and depth were correlated with taxonomic and functional

325 communities in both spring and autumn, with one exception (between depth and

326 functional communities in spring; Table 7). Both taxonomic and functional

327 communities were strongly correlated with a greater number of hydrological metrics

328 in spring, whereas substrate characteristics were most important in autumn. The \%

329 of S1 zero-flow days had the greatest influence on both taxonomic and functional

330 community composition in spring (as denoted by the greatest $F$ value), whereas in

331 autumn the \% of silt and gravel exerted the greatest influence on taxonomic and

332 functional communities, respectively (Table 7). Functional communities

333 demonstrated a greater association with hydrological metrics in both spring and

334 autumn (as indicated by the greater $F$ values for \% zero-flow days).

335 Perennial and non-perennial taxonomic communities separated along RDA axis 1 in 336 spring, which was correlated with hydrological metrics describing flow permanence

337 (i.e. \% S1 zero-flow days and mean S1; Figure 3a). Variation in community

338 composition within non-perennial sites was associated with substrate conditions (\%

339 gravel) and wetted channel characteristics (width, depth), as reflected by separation

340 along RDA axis 2 . The two RDA axes accounted for $14.13 \%$ of variance and were

341 highly significant $(p<0.05$; Table 7$)$. There was some evidence of a perennial and

342 non-perennial site separation along RDA axis 1 which represented mean winter

343 discharge, mean summer discharge and depth for autumn taxonomic communities

344 (Figure 3b; RDA axes accounted for $13.86 \%$ of variance; Table 7 ). Variation within

345 flow permanence regimes was correlated with \% pebbles. In both seasons,

346 community variability associated with the environmental parameters was greatest in

347 perennial sites. 
349 Separation of perennial and non-perennial sites was evident in spring functional 350 communities along RDA axis 1, which was associated with descriptors of flow 351 permanence regimes (\% S1 - zero-flow days for the previous summer) and wetted 352 width (Figure 3c). Positioning of assemblages along RDA axis 2 reflected within flow 353 regime variation in community composition associated with mean winter discharge 354 (mean W1) and the two axes collectively explained $27.77 \%$ of the variation in 355 community composition. In contrast, separation of perennial and non-perennial 356 functional assemblages was not evident in autumn (Figure 3d; RDA axes accounted 357 for $18.92 \%$ of variance; Table 7 ). In both seasons, variability in communities 358 associated with the environmental parameters was greatest in non-perennial sites.

\section{4. Discussion}

360 Characterising broad-scale macroinvertebrate responses to hydrological variability 361 and flow permanence is challenging, because interacting local conditions such as 362 antecedent hydrological conditions, the core taxa present, and habitat characteristics 363 simultaneously influence ecological responses (Chakona, Phiri, Magadza, \& 364 Brendonck, 2008; Leigh et al., 2016). Tackling this ecological complexity, our 26365 year study of taxonomic and functional macroinvertebrate communities demonstrated that the dynamic, heterogeneous communities of non-perennial 367 streams can be captured effectively using paired biological-hydrological data 368 collected over multi-decade timescales. Flow permanence, wetted width and depth 369 were primary drivers of macroinvertebrate community composition, and the 370 importance of substrate conditions increased in autumn.

\subsection{Macroinvertebrate responses within perennial and non-perennial river}


373 Our research, conducted in a wet, cool temperate region, builds on short-term

374 oceanic-climate studies which have found that perennial and non-perennial river

375 reaches support discrete taxonomic macroinvertebrate assemblages (Wood et al., 376 2005; Stubbington et al., 2011; White et al., 2018). We found that these differences 377 persisted long term (26 years) despite evident intra-annual variability in hydrological 378 conditions and low spatial / temporal extent of flow permanence in oceanic regions 379 compared to dryland regions, including the close proximity of perennial reaches. 380

381 Other studies conducted over shorter time periods have reported that taxonomic 382 community composition at perennial and non-perennial sites may converge if 383 sampling is conducted after several months of continuous flow, reflecting 384 recolonisation by taxa persisting in refuges. However, our clear separation of sites 385 highlights the importance of long-term studies that represent the range and dominant 386 hydrological conditions experienced at a location (Delucchi, 1998; Wood et al., 2005; 387 Sheldon et al., 2010). We found differences in the composition and alpha diversity of 388 taxonomic and functional communities in perennial and non-perennial river reaches. 389 Flow permanence regime was the primary driver of diversity differences, with 390 perennial sites supporting higher values than non-perennial sites regardless of 391 season (Bonada et al., 2007; Datry, 2012; Schriever et al., 2015; Suárez et al., 392 2017).

393 We did, however, note subtle differences between the two methodological 394 approaches, with functional communities being more strongly influenced by flow 395 permanence regime (and the interaction with site) whilst taxonomic communities 396 demonstrated greater differences among sites. Communities were likely responding 397 to habitat-specific flow velocities, hydraulic habitats and substrate conditions (Lane 
398 Pasternack, \& Sandoval-Solis, 2018; White et al., 2019). Functional responses may 399 be less sensitive to small-scale fluctuations in hydrological conditions due to their 400 high stability in space and time (Statzner \& Bêche, 2010), meaning that extreme 401 conditions may be required to eliminate enough taxa to cause detectable 402 compositional shifts (Schriever et al., 2015). Alpha diversity also demonstrated a 403 significant interaction between site and flow permanence regime, indicating that site404 specific environmental controls may play a more important role in the structuring of 405 communities compared to general hydrological patterns (Bonada et al., 2007). 406

407 Broad patterns of compositional differences among non-perennial and perennial river 408 reaches reflected the distributions of taxa adapted to the prevailing hydrological 409 conditions. Non-perennial river reaches were characterised by taxa with traits 410 promoting resistance to drying events, i.e. cocoons and housing against desiccation 411 (Bogan et al., 2014; Leigh et al., 2016). For example, some Lymnaeidae species are 412 characteristic of non-perennial waterbodies and are a desiccation-tolerant 413 component of the aquatic invertebrate 'seedbank' (Stubbington, Gunn, Little, Worrall, 414 \& Wood, 2016). Galba truncatula was the dominant lymnaeid in our study stream, is 415 capable of air-breathing, and has previously been identified as indicative of 416 intermittent stream reaches (Stubbington et al., 2009; White et al., 2018). Surface 417 swimmers were found to indicative of non-perennial sites reflecting the presence of 418 lentic habitats when flow ceases (Hill and Milner, 2019). Coleopterans of the family 419 Dytiscidae were characteristic of non-perennial sites, possessing adaptations which 420 enable dry-phase persistence, such as air-breathing, an impermeable cuticle that 421 reduces water loss (Holdgate, 1956), and overland flight which enables dispersal 422 between disconnected waterbodies (Jackson, 1952). Lumbricidae were also 
423 indicative of these sites and likely included aquatic, semi-aquatic and terrestrial

424 species (Stubbington et al., 2016).

425 Taxa characterising the perennial reaches had traits reliant on continuous water 426 availability, such as feeding on aquatic prey (e.g. Erpobdellidae, Glossiphoniidae)

427 and permanent attachment to a substrate (e.g. Hydrobiidae). Although predators can 428 thrive during flow recession due to the concentration of prey within a declining 429 habitat area (Acuña et al., 2005), their typically large body sizes can prevent access 430 to saturated refuges during dry phases, causing population densities to decline 431 (Ledger, Edwards, Brown, Milner, \& Woodward, 2011). Perennial reaches were also 432 characterised by $K$-selected traits, with the prevalence of large-bodied and long-lived 433 taxa which exhibit low voltinism typically increasing with the hydroperiod (wet-phase 434 duration; Corti, Kohler, \& Sparks, 1996; García-Roger et al., 2013).

435 Notable seasonal differences in indicator taxa within non-perennial reaches included 436 taxa with smaller body sizes, aquatic passive dispersal and adult aquatic stages in 437 autumn. Taxa possessing such traits include Crangonyctidae and Corixidae, which 438 were characteristic of non-perennial reaches. These taxa are associated with slow439 flowing and/or lentic waters (Jass \& Klausmeier, 2003; Van de Meutter, Stoks, \& De 440 Meester, 2006; Wiberg-Larsen, 2008), and may have inhabited pools and ponded 441 habitats (Hill \& Milner, 2018). Habitat complexity may have enabled their localised 442 persistence after flow resumption in autumn (Lane et al., 2018), prior to likely 443 displacement by high winter flows. Indicator traits unique to spring included nymph 444 life stages and temporary attachment to substrates. Such taxa are likely to be insects 445 with seasonal life cycle dynamics, for example Simuliidae, whose abundance peaked 446 in spring with temporary attachment enabling rapid migration to refuges as drying 
447 commences. That such taxa were not non-perennial indicators suggests non-

448 discriminant seasonal colonisation of reaches with contrasting flow permanence 449 regimes.

450 Indicator values were generally higher for functional traits than taxa, highlighting the 451 potential of traits as ecological indicators of environmental conditions (Sarremejane 452 et al., 2017a). Functional responses may facilitate clearer observations of responses 453 to changing environmental conditions (such as hydrology) as there is less 'noise' in 454 datasets, due to functional redundancy (García-Roger, 2017), and some traits such 455 as resistance forms may enable the persistence of multiple taxa at non-perennial 456 sites (Boersma et al., 2014). Including trait-based assessments in ecological 457 monitoring may therefore enhance fundamental understanding of the links between 458 biodiversity and ecosystem function (Monk et al., 2018; Reiss, Bridle, Montoya, \& 459 Woodward, 2009).

\subsection{Heterogeneity in macroinvertebrate community composition of perennial} and non-perennial river reaches

462 Taxonomic and functional communities inhabiting non-perennial sites were

463 characterised by greater heterogeneity than perennial river reaches. Such variability 464 may reflect higher temporal and spatial habitat heterogeneity (Bonada et al., 2007; 465 Datry et al., 2014b; Cid et al., 2017), which allows a diverse range of aquatic taxa to 466 sequentially inhabit lotic and lentic instream habitats (Bogan \& Lytle, 2007; Munné \& 467 Prat, 2011; Giam et al., 2017; Tonkin et al., 2017). Overall, functional assemblage 468 compositions were temporally and spatially stable in this study (demonstrated by the 469 significantly lower heterogeneity values compared to taxonomic communities), 470 despite hydrological variability which encompassed drought events and periods of 
471 above-average precipitation, suggesting their potential as stable indicator (Bêche et

472 al., 2006; Statzner \& Bêche, 2010; Dolédec, Tilbian \& Bonada, 2017).

473 Some evidence of seasonal effects was detected in community heterogeneity, with

474 non-perennial sites demonstrating reduced heterogeneity in autumn in both

475 taxonomic and functional communities, whereas perennial reaches did not differ in

476 heterogeneity among seasons. Autumn is typically when the influence of flow

477 permanence and low flows on aquatic communities is most evident in temperate-

478 zone streams, due to recent flow resumption. Non-perennial sites may be more

479 temporally heterogeneous in spring dependent on dispersal of recolonists from

480 refuges following flow resumption; these processes are likely to be highly variable

481 (Cañedo-Argüelles et al., 2015; Sarremejane, Mykrä, Bonada, Aroviita, \& Muotka,

482 2017b). For example, Perrow, Leeming, England, \& Tomlinson (2007) noted specific

483 flowing-water species at some Misbourne sites after flow resumption following the

$4841996 / 1997$ drought that had not been recorded elsewhere in the river, thereby

485 increasing heterogeneity.

486 4.3 Perennial and non-perennial macroinvertebrate community associations

487 with environmental variables

488 Our results indicate that hydrological metrics were the primary factors structuring

489 functional and taxonomic macroinvertebrate communities, most notably in spring,

490 and for functional communities. Trait-based approaches may provide a robust means

491 of assessing ecological responses to hydrology across regions with different taxon

492 pools (White et al., 2017a). The high temporal stability in functional communities can

493 help facilitate discrimination of spatial environmental differences in assemblage

494 composition (Cid et al., 2016; García-Roger 2017) and may explain why spring 
495 functional communities demonstrated the strongest association to a measured 496 environmental parameter.

497 The \% of zero-flow days in the previous summer (April-September) was of greatest 498 importance in structuring spring communities. Wetted channel characteristics were 499 also significant drivers, with width demonstrating a significant correlation in all four 500 models and depth in all but one. Autumn communities were more strongly correlated 501 with substrate conditions (\% silt, pebble or gravel) that characterise the legacy of 502 hydraulic conditions. These results provide further evidence that localised hydraulic 503 observations may improve the characterisation of forces that biota are responding to 504 at the time of sampling compared to the use of discharge-related statistics alone 505 (Malcolm et al., 2012b; Monk et al., 2018; White et al., 2019)

506 Functional redundancy may promote community resilience to environmental variation 507 (Schriever et al., 2015; Oliver et al., 2015) and may explain the lack of separation 508 between functional communities in perennial and non-perennial river reaches in the 509 autumn. Non-perennial communities in autumn may represent a subset of those from 510 perennial reaches (Arscott et al., 2010; Datry, 2012; Datry et al., 2014a), comprising 511 resistant representatives that are able to persist in moist habitats/substrates (e.g. 512 Galba truncatula; Stubbington \& Datry, 2013). In contrast, spring communities also 513 include taxa which may have recolonised non-perennial reaches from perennial 514 sources upstream or persisted in-situ following flow resumption. The composition of 515 functional processes may therefore have been altered resulting in separation of the 516 two functional flow permanence communities during spring. In contrast taxonomic 517 composition demonstrated some overlap in perennial and non-perennial river 518 reaches but differences in composition were evident in both spring and autumn. 


\section{Conclusion}

520 As global recognition of the biodiversity value and ecosystem service provision of 521 temporary streams increases (Acuña et al., 2017; Datry et al., 2017b), so does their 522 extent, in response to interacting climate change and water resource pressures.

523 Ecologically robust conservation and management strategies are therefore required, 524 and will be most effective if informed by analyses that interpret both taxonomic and 525 functional responses to flow permanence in the context of long-term intra- and inter526 annual hydrological variability (Döll \& Schmied, 2012; Watts et al., 2015). Our results 527 suggest that functional approaches could be a robust means of assessing ecological 528 responses to hydrological drivers. We call for future research that builds on our work 529 to further inform the protection of both perennial and non-perennial streams as they 530 adapt to ongoing environmental change.

\section{Acknowledgements}

532 Many thanks to Geoff Angel and Rebecca Ross from the Environment Agency of 533 England for the provision of the hydrological data and the many Environment Agency 534 staff who collected the hydrological and biological data. Thanks also go to Romain 535 Sarremejane for the calculation of flow-permanence flow metrics and Diana 536 Hammond for providing background information about the river. Matthew Hill is 537 thanked for useful discussions pertaining to the analyses of the study. The views 538 expressed within the paper are those of the authors and not necessarily those of 539 their organisations. We thank the anonymous reviewers who for their helpful and 540 constructive comments.

541 Data availability: The daily mean discharge data for sites 1 and 6 can be obtained

542 freely from the National River Flow Archive at https://nrfa.ceh.ac.uk/data using the 543 station codes of 39127 and 39102. Biological data for all sites and spot gauged data 
544 (sites 2-5) are available on request from the Environment Agency via

545 http://apps.environment-agency.gov.uk/contact/.

\section{$547 \quad$ List of Figures}

548 Figure 1. Locations of biotic and abiotic parameters used in the study and the flow 549 permanence regime of the River Misbourne, UK.

550 Figure 2. Typical hydrographs of discharge regimes at: (a) non-perennial and; (b) 551 perennial river reaches on the River Misbourne during the study period. Note:

552 gauging records were not present at sites 1-4 until 1994. Site 3 (non-perennial) and 553 site 6 (perennial) are shown.

554 Figure 3. Redundancy analysis (RDA) of: (a) spring taxonomic; (b) autumn 555 taxonomic; (c) spring functional and; (d) autumn functional macroinvertebrate 556 community composition on the River Misbourne. Perennial sites = grey; non557 perennial sites $=$ black. Only significant environmental parameters influencing faunal 558 data are presented. \% W1 zero-flow days = \% of winter zero-flow days; \% S1 zero559 flow days and \% S2 zero-flow days = \% of summer zero-flow days; mean W1 = 560 mean winter discharge; mean S1 and S2 = mean summer discharge. Two years of 561 antecedent summer (April-September) and one year of winter (October-March) data 562 were used. Note the difference in scale between panes a-b and c-d. 


\section{References}

564 Acuña, V., Muñoz, I., Giorgi, A., Omella, M., Sabater, F., \& Sabater, S. (2005).

565 Drought and postdrought recovery cycles in an intermittent Mediterranean stream:

566 Structural and functional aspects. Journal of the North American Benthological 567 Society, 24, 919-933. doi:10.1899/04-078.1

568 Acuña, V., Hunter, M. \& Ruhí, A. (2017). Managing temporary streams and rivers as 569 unique rather than second-class ecosystems. Biological Conservation, 211, pp.12570 19.doi: 10.1016/j.biocon.2016.12.025

571 Arscott, D. B., Larned, S., Scarsbrook, M. R., \& Lambert, P. (2010). Aquatic 572 invertebrate community structure along an intermittence gradient: Selwyn River, New 573 Zealand. Journal of the North American Benthological Society, 29, 530-545. doi: 574 10.1899/08-124.1

575 Bartoń, K. (2016) MuMIn: Multi-Model inference. R package version 1.15.6.

576 Bêche, L. A., Connors, P. G., Resh, V. H., \& Merenlender A. M. (2009). Resilience of 577 fishes and invertebrates to prolonged drought in two California streams. Ecography, 578 32, 778-788. doi:10.1111/j.1600-0587.2009.05612.x

579 Bêche, L. A., Mcelravy, E. P., \& Resh, V. H. (2006). Long-term seasonal variation in 580 the biological traits of benthic-macroinvertebrates in two Mediterranean-climate 581 streams in California, USA. Freshwater Biology, 51, 56-75. doi:10.1111/j.1365$582 \quad 2427.2005 .01473 . x$

583 Boersma, K. S., Bogan, M. T., Henrichs, B. A., \& Lytle, D. A. (2014). Invertebrate 584 assemblages of pools in arid-land streams have high functional redundancy and are 585 resistant to severe drying. Freshwater Biology, 59, 491-501. doi:10.1111/fwb.12280

586 Bogan, M. T., Boersma, K. S., \& Lytle, D. A. (2013). Flow intermittency alters 587 longitudinal patterns of invertebrate diversity and assemblage composition in an 588 arid-land stream network. Freshwater Biology, 58, 1016-1028. doi:10.1111/fwb.1210

589 Bogan, M.T., Boersma, K.S. \& Lytle, D.A. (2015). Resistance and resilience of 590 invertebrate communities to seasonal and supraseasonal drought in arid-land 591 headwater streams. Freshwater Biology, 60, 2547-2558.doi:-10.1111/fwb.12522

592 Bogan, M. T., \& Lytle, D. A. (2007). Seasonal flow variation allows 'time-sharing' by 593 disparate aquatic insect communities in montane desert streams. Freshwater 594 Biology, 52, 290-304. doi:10.1111/j.1365-2427.2006.01691.x

595 Bonada, N., Rieradevall, M., \& Prat, N. (2007). Macroinvertebrate community 596 structure and biological traits related to flow permanence in a Mediterranean river 597 network. Hydrobiologia, 589, 91-106. doi:10.1007/s10750-007-0723-5 
598 Bonada, N., Rieradevall, M., Prat, N., \& Resh, V. H. (2006). Benthic

599 macroinvertebrate assemblages and macrohabitat connectivity in Mediterranean-

600 climate streams of northern California. Journal of the North American Benthological

601 Society, 25, 32-43. doi:10.1899/0887-3593(2006)25[32:BMAAMC]2.0.CO;2

602 Cañedo-Argüelles, M., Boersma, K. S., Bogan, M. T., Olden, J. D., Phillipsen, I., 603 Schriever, T. A. \& Lytle, D. A. (2015). Dispersal strength determines

604 meta-community structure in a dendritic riverine network. Journal of Biogeography,

605 42, 778-790. doi:10.1111/jbi.12457

606 Cañedo-Argüelles, M., Bogan, M. T., Lytle, D. A., \& Prat, N. (2016). Are

607 Chironomidae (Diptera) good indicators of water scarcity? Dryland streams as a 608 case study. Ecological Indicators, 71, 155-162. doi:10.1016/j.ecolind.2016.07.002

609 Chakona, A., Phiri, C., Magadza, C. H., \& Brendonck, L. (2008). The influence of 610 habitat structure and flow permanence on macroinvertebrate assemblages in 611 temporary rivers in northwestern Zimbabwe. Hydrobiologia, 607, 199-209.

612 doi:10.1007/s10750-008-9391-3

613 Chessman, B. C. (2015). Relationships between lotic macroinvertebrate traits and 614 responses to extreme drought. Freshwater Biology, 60, 50-63.

615 doi:10.1111/fwb.12466

616 Chevene, F., Doléadec, S., \& Chessel, D. (1994). A fuzzy coding approach for the 617 analysis of long-term ecological data. Freshwater Biology, 31, 295-309.

618 doi:1111/j.1365-2427.1994.tb01742.x

619 Cid, N., Bonada, N., Carlson, S. M., Grantham, T. E., Gasith, A., \& Resh, V. H. 620 (2017). High variability is a defining component of Mediterranean-climate rivers and 621 their biota. Water, 9, 52. doi:10.3390/w9010052

622 Cid, N., Verkaik, I., García-Roger, E. M., Rieradevall, M., Bonada, N., Sánchez623 Montoya, M. M., ... Buffagni, A. (2016). A biological tool to assess flow connectivity 624 in reference temporary streams from the Mediterranean Basin. Science of the Total 625 Environment, 540, 178-190. doi:10.3390/w9010052

626 Corti, D., Kohler, S. L., \& Sparks, R. E. (1996). Effects of hydroperiod and predation 627 on a Mississippi River floodplain invertebrate community. Oecologia, 109, 154-165. 628 doi: $10.1007 / \mathrm{s} 004420050070$

629 Datry, T. (2012). Benthic and hyporheic invertebrate assemblages along a flow 630 intermittence gradient: effects of duration of dry events. Freshwater Biology, 57, 563631 574. doi.org/10.1111/j.1365-2427.2011.02725.x 
632 Datry, T., Boulton, A. J., Bonada, N., Fritz, K., Leigh, C., Sauquet, E., ... Dahm, C. N. 633 (2017b). Flow intermittence and ecosystem services in rivers of the Anthropocene. 634 Journal of Applied Ecology, 55, 353-364. doi:10.1111/1365-2664.12941

635 Datry, T., Larned, S., Fritz, K., Bogan, M., Wood, P. J., Meyer, E., \& Santos, A. 636 (2014a). Broad-scale patterns of invertebrate richness and community composition 637 in temporary rivers: effects of flow intermittence. Ecography, 37, 94-104.

638 doi:10.1111/j.1600-0587.2013.00287.x

639 Datry, T., Larned, S. T., \& Tockner, K. (2014b). Intermittent rivers: a challenge for 640 freshwater ecology. BioScience, 64, 229-235. doi:10.1093/biosci/bit027

641 Datry, T., Vander Vorste, R., Goïtia, E., Moya, N., Campero, M., Rodriguez, F., ... 642 Oberdorff, T. (2017a). Context-dependent resistance of freshwater invertebrate 643 communities to drying. Ecology and Evolution, 7, 3201-3211. doi:

644 10.1002/ece3.2870. doi:10.1111/1365-2664.12941

645 Datry, T., Boulton, A._., Bonada, N., Fritz, K., Leigh, C., Sauquet, E., Tockner, K., 646 Hugueny, B. \& Dahm, C.N. (2018). Flow intermittence and ecosystem services in 647 rivers of the Anthropocene. Journal of Applied Ecology, 55, 353-364.

648 De Cáceres, M., \& Jansen, F. (2016). Indicspecies: Relationship between species 649 and groups of sites. R package version 1.7.6. Available at https://cran.r650 project.org/web/packages/indicspecies/index.html

651 De Cáceres, M., Legendre, P., Wiser, S. K., \& Brotons, L. (2012). Using species 652 combinations in indicator value analyses. Methods in Ecology and Evolution, 3, 973653 982. doi:10.1111/j.2041-210X.2012.00246.x

654 Delucchi, C. M. (1988). Comparison of community structure among streams with 655 different temporal flow regimes. Canadian Journal of Zoology, 66, 579-586.

656 doi:10.1139/z88-085

657 Descloux, S., Datry, T., \& Usseglio-Polatera, P. (2014). Trait-based structure of 658 invertebrates along a gradient of sediment colmation: Benthos versus hyporheos 659 responses. Science of the Total Environment, 466, 265-276.

660 doi:10.1016/j.scitotenv.2013.06.082

661 Döll, P., \& Schmied, H. M. (2012). How is the impact of climate change on river flow 662 regimes related to the impact on mean annual runoff? A global-scale analysis. 663 Environmental Research Letters, 7, p.014037. doi:10.1088/1748-9326/7/1/014037

664 Dolédec, S., Tilbian, J., \& Bonada, N. (2017). Temporal variability in taxonomic and 665 trait composition of invertebrate assemblages in two climatic regimes with 666 contrasting flow regimes. Science of the Total Environment, 599-600, 1912-1921. 667 doi:10.1016/j.scitotenv.2017.05.057 
668 Dufrêne, M., \& Legendre, P. (1997). Species assemblages and indicator species: the 669 need for a flexible asymmetrical approach. Ecological Monographs, 67, 345-366. 670 doi:10.1890/0012-9615(1997)067[0345:SAAIST]2.0.CO;2

671 Dunbar, M. J., Pederson, M. L., Cadman, D., Extence, C. A., Waddingham, J., 672 Chadd, R. P., \& Larsen, S. E. (2010a). River discharge and local-scale physical 673 habitat influence macroinvertebrate LIFE scores. Freshwater Biology, 55, 226-242. 674 doi.org/10.1111/j.1365 - 2427.2009.02306.x

675 Dunbar, M. J., Warren, M., Extence, C. A., Baker, L., Cadman, D., Mould, D. J., ... 676 Chadd, R. P. (2010b). Interaction between macroinvertebrates, discharge and 677 physical habitat in upland rivers. Aquatic Conservation: Marine and Freshwater 678 Ecosystems, 20, 31-44. doi: 10.1002/aqc.1089

679 Durance, I., \& Ormerod, S. J. (2009). Trends in water quality and discharge 680 confound long-term warming effects on river macroinvertebrates. Freshwater 681 Biology, 54, 388-405. doi:10.1111/j.1365-2427.2008.02112.x

682 Fox, J \& Weisberg, S. (2011). An $\{R\}$ Companion to Applied Regression, Second 683 Edition. Thousand Oaks CA: Sage.

684 García-Roger, E. M. (2017). Benthic invertebrate community structure and biological 685 traits along a flow intermittence gradient in a Mediterranean stream. Fundamental 686 and Applied Limnology, 190, 117-132. doi:10.1127/fal/2017/0984

687 García-Roger, E. M., Sánchez-Montoya, M. D. M., Cid, N., Erba, S., Karaouzas, I., 688 Verkaik, I., ... DeMartini, D. (2013). Spatial scale effects on taxonomic and biological 689 trait diversity of aquatic macroinvertebrates in Mediterranean streams. Fundamental 690 and Applied Limnology, 183, 89-105. doi:10.1127/1863-9135/2013/0429

691 Gallart, F., Prat, N., García-Roger, E.M., Latron, J., Rieradevall, M., Llorens, P., 692 Barberá, G.G., Brito, D., De Girolamo, A.M., Porto, A.L. \& Buffagni, A. (2012). A 693 novel approach to analysing the regimes of temporary streams in relation to their 694 controls on the composition and structure of aquatic biota. Hydrology and Earth 695 System Sciences, 16(9), 3165-3182. Doi: 10.5194/hess-16-3165-2012.

696 Gayraud, S., Statzner, B., Bady, P., Haybachp, A., Schöll, F., Usseglio-Polatera, P. 697 and Bacchi, M., 2003. Invertebrate traits for the biomonitoring of large European 698 rivers: an initial assessment of alternative metrics. Freshwater Biology, 48(11), 2045699 2064. doi: 10.1046/j.1365-2427.2003.01139.x

700 Gordon, N. D., McMahon, T. A., Finlayson, B. L., Gippel, C. J. \& Nathan, R. J. (2004) 701 Stream hydrology: An introduction for ecologists, (2nd ed.) Chichester, UK: Wiley. 702 pp. 1-448. 
703 Giam, X., Chen, W., Schriever, T. A., Van Driesche, R., Muneepeerakul, R., Lytle, D.

704 A., \& Olden, J. D. (2017). Hydrology drives seasonal variation in dryland stream 705 macroinvertebrate communities. Aquatic Sciences, 79, 705-717.

706 doi:10.1007/s00027-017-0530-7

707 Hill, M. J., \& Milner, V. S. (2018). Ponding in intermittent streams: A refuge for lotic 708 taxa and a habitat for newly colonising taxa? Science of the Total Environment, 628, 709 1308-1316. doi:10.1016/j.scitotenv.2018.02.162

710 Holdgate, M. W. (1956). Transpiration through the cuticles of some aquatic insects.

711 Journal of Experimental Biology, 33, 107-118.

712 Jackson, D. J. (1952). Observations on the capacity for flight of water beetles.

713 Proceedings of the Royal Entomological Society, 27, 57-70.

714 Jass, J. \& Klausmeier, B. (2003). Utilization of lotic, lentic, and temporary habitats by 715 the amphipod Crangonyx gracilis. Journal of Freshwater Ecology, 18, 635-638. doi: $71610.1080 / 02705060.2003 .9664005$

717 Lane, B. A., Pasternack, G. B., \& Sandoval-Solis, S., 2018. Integrated analysis of 718 flow, form, and function for river management and design testing. Ecohydrology, 719 p.e1969. doi:10.1002/eco.1969

720 Larsen, S., \& Ormerod, S. J. (2010a). Low-level effects of inert sediments on 721 temperate stream invertebrates. Freshwater Biology, 55, 476-486.

722 doi:10.1111/j.1365-2427.2009.02282

723 Larsen, S., \& Ormerod, S. J. (2010b). Combined effects of habitat modification on 724 trait composition and species nestedness in river invertebrates. Biological

725 Conservation, 143, 2638-2646. doi:10.1016/j.biocon.2010.07.006

726 Ledger, M. E., Edwards, F. K., Brown, L. E., Milner, A. M., \& Woodward, G. (2011). 727 Impact of simulated drought on ecosystem biomass production: an experimental test 728 in stream mesocosms. Global Change Biology, 17, 2288-2297. doi:-10.1111/j.1365729 2486.2011.02420.x

730 Leigh, C., Bonada, N., Boulton, A. J., Hugueny, B., Larned, S. T., Vander Vorste, R., 731 \& Datry, T. (2016). Invertebrate assemblage responses and the dual roles of 732 resistance and resilience to drying in intermittent rivers. Aquatic Sciences, 78, 291733 301. doi:10.1007/s00027-015-0427-2

734 Leigh, C., Boulton, A. J., Courtwright, J. L., Fritz, K., May, C. L., Walker, R. H., \& 735 Datry, T. (2015). Ecological research and management of intermittent rivers: an 736 historical review and future directions. Freshwater Biology, 61, 1181-1199.

737 doi:10.1111/fwb.12646 
738 Leigh, C., \& Datry, T. (2017). Drying as a primary hydrological determinant of 739 biodiversity in river systems: A broad-scale analysis. Ecography, 40, 487-499. 740 doi: $10.1111 /$ ecog. 02230

741 Malcolm, C. E. L., Young, A. R., Willmott, E. R., Holmes, M. G. R., \& Gosling, R. D. 742 modelled flows (2012a). Proceedings of BHS $11^{\text {th }}$ National Hydrology Symposium, 743 Dundee, UK, pp. 1-7. doi:10.7558/bhs.2012.ns31

744 Malcolm, I. A., Gibbins, C. N., Soulsby, C., Tetzlaff, D., \& Moir, H. J. (2012b). The 745 influence of hydrology and hydraulics on salmonids between spawning and 746 emergence: implications for the management of flows in regulated rivers. Fisheries 747 Management and Ecology, 19, 464- 474. doi:10.1111/j.1365-2400.2011.00836.x

748 Marsh, T., Cole, G., \& Wilby R. (2007). Major droughts in England and Wales, 1800 749 2006. Weather, 62, 87-93.

750 Marsh, T., Parry S., Kendon M. C., \& Hannaford J. (2013). The 2010-12 Drought and 751 Subsequent Extensive Flooding. Centre for Ecology \& Hydrology: Wallingford, UK, 752 pp. 1-64. Available at https://nora.nerc.ac.uk/id/eprint/503643/1/N503643CR.pdf

753 Mathers, K. L., Chadd, R. P., Dunbar, M. J., Extence, C. A., Reeds, J., Rice, S. P., \& 754 Wood, P. J. (2016). The long-term effects of invasive signal crayfish (Pacifastacus 755 leniusculus) on instream macroinvertebrate communities. Science of the Total 756 Environment, 556, 207-218. doi:10.1016/j.scitotenv.2016.01.215

757 Menezes, S., Baird, D. J. \& Soares, A. M. (2010). Beyond taxonomy: a review of 758 macroinvertebrate trait-based community descriptors as tools for freshwater 759 biomonitoring. Journal of Applied Ecology, 47, 711-719. doi:10.1111/j.1365$760 \quad 2664.2010 .01819 . x$

761 Monk, W.A., Compson, Z.G., Armanini, D.G., Orlofske, J.M., Curry, C.J., Peters, 762 D.L., Crocker, J.B. and Baird, D.J., 2018. Flow velocity-ecology thresholds in 763 Canadian rivers: A comparison of trait and taxonomy-based approaches. Freshwater 764 Biology, 63, 891-905. Doi: 10.1111/fwb.13030.

765 Monk, W. A., Wood, P. J., Hannah, D. M., Extence, C. A., Chadd, R. P., \& Dunbar, 766 M. J. (2012). How does macroinvertebrate taxonomic resolution influence 767 ecohydrological relationships in riverine ecosystems. Ecohydrology, 5, 36-45. 768 doi:10.1002/eco.192

769 Monk, W. A., Compson, Z. G., Armanini, D. G., Orlofske, J. M., Curry, C. J., Peters, 770 D. L., ... Baird, D. J. (2018). Flow velocity-ecology thresholds in Canadian rivers: A 771 comparison of trait and taxonomy based approaches. Freshwater Biology, 63, 891772 905. doi:10.1111/fwb. 13030 
773 Munné, A., \& Prat, N. (2011). Effects of Mediterranean climate annual variability on

774 stream biological quality assessment using macroinvertebrate communities.

775 Ecological Indicators, 11, 651-662. doi:10.1016/j.ecolind.2010.09.004

776 Murray-Bligh, J. (1999). Procedures for Collecting and Analysing Macroinvertebrate 777 Samples - BT0001. Environment Agency: Bristol, UK, pp. 1-176.

778 NRFA (2017). National River Flow Archive. 39102 - Misbourne at Denham Lodge.

779 Available at http://nrfa.ceh.ac.uk/data/station/info/39102 [accessed 26 April 2017]

780 Oksanen, J., F. G., Blanchet, M., Friendly, R., Kindt, P., Legendre, D., McGlinn, P. 781 R., ... Wagner, H. (2015). Vegan: Community ecology package. R package version 782 2.3-1. Available at http://CRAN.R-project.org/package=vegan

783 Perrow, M., Leeming, D. J., England, J. A. \& Tomlinson, M. (2007). Life after low 784 flow-ecological recovery of the River Misbourne. British Wildlife, 18, 335-347.

785 Pinheiro J, Bates D, DebRoy S, Sarkar D, \& R Core Team (2019). nlme: Linear and 786 Nonlinear Mixed Effects Models. R package version 3.1-139

787 Poff, N. L., \& Ward, J. V. (1989). Implications of streamflow variability and 788 predictability for lotic community structure: a regional analysis of streamflow patterns. 789 Canadian Journal of Fisheries and Aquatic Sciences, 46, 1805-1818.

790 doi:10.1139/f89-228

791 R Development Core Team. (2017) A language and environment for statistical 792 computing. Foundation for Statistical Computing, Vienna.

793 Reiss, J., Bridle, J. R., Montoya, J. M., \& Woodward, G. (2009). Emerging horizons 794 in biodiversity and ecosystem functioning research. Trends in Ecology \& Evolution, 795 24, 505-514. Doi:10.1016/j.tree.2009.03.018.

796 Rolls, R. J., Heino, J., \& Chessman, B. C. (2016). Unravelling the joint effects of flow 797 regime, climatic variability and dispersal mode on beta diversity of riverine 798 communities. Freshwater Biology, 61, 1350-1364. doi:10.1111/fwb.12793

799 Sarremejane, R., Cañedo-Argüelles, M., Prat, N., Mykrä, H., Muotka, T., \& Bonada, 800 N. (2017a). Do metacommunities vary through time? Intermittent rivers as model 801 systems. Journal of Biogeography, 44, 2752- 2763. doi:10.1111/jbi.13077

802 Sarremejane, R., Mykrä, H., Bonada, N., Aroviita, J., \& Muotka, T. (2017b). Habitat 803 connectivity and dispersal ability drive the assembly mechanisms of 804 macroinvertebrate communities in river networks. Freshwater Biology, 62, 1073805 1082. doi:10.1111/fwb.12926

806 Schriever, T. A., Bogan, M. T., Boersma, K. S., Cañedo-Argüelles, M., Jaeger, K. L., 807 Olden, J. D., \& Lytle, D. A. (2015). Hydrology shapes taxonomic and functional 
808 structure of desert stream invertebrate communities. Freshwater Science, 34, 399809 409. doi:10.1086/680518

810 Sheldon, F., Bunn, S. E., Hughes, J. M., Arthington, A. H., Balcombe, S. R., \& 811 Fellows, C. S. (2010). Ecological roles and threats to aquatic refugia in arid 812 landscapes: dryland river waterholes. Marine and Freshwater Research, 61, 885813 895. doi:10.1071/MF09239

814 Smith, H., \& Wood, P. J. (2002). Flow permanence and macroinvertebrate 815 community variability in limestone spring systems. Hydrobiologia, 487, 45-58. 816 doi:10.1023/A:1022932303652

817 Statzner, B., \& Bêche, L. A. (2010). Can biological invertebrate traits resolve effects 818 of multiple stressors on running water ecosystems? Freshwater Biology, 55, 80-119. 819 doi:10.1111/j.1365-2427.2009.02369.x

820 Stubbington, R., Greenwood, A.M., Wood, P.J., Armitage, P.D., Gunn, J. \& 821 Robertson, A.L. (2009). The response of perennial and temporary headwater stream 822 invertebrate communities to hydrological extremes. Hydrobiologia, 630, 299-312. doi: 823 10.1007/s10750-009-9823-8

824 Stubbington, R., Wood, P.J., Reid, I. \& Gunn, J. (2011). Benthic and hyporheic 825 invertebrate community responses to seasonal flow recession in a 826 groundwater-dominated stream. Ecohydrology, 4, 500-511. Doi:10.1002/eco.168

827 Stubbington, R. \& Datry, T. (2013). The macroinvertebrate seedbank promotes 828 community persistence in temporary rivers across climate zones. Freshwater 829 Biology, 58, 1202-1220. doi: 10.1111/fwb.12121. doi: 10.1111/fwb.12121.

830 Stubbington, R., Gunn, J., Little, S., Worrall, T. P., \& Wood, P. J. (2016). 831 Macroinvertebrate seedbank composition in relation to antecedent duration of drying 832 and multiple wet-dry cycles in a temporary stream. Freshwater Biology, 61, 1293833 1307. doi:10.1111/fwb.12770

834 Stubbington, R., Wood, P. J., \& Boulton, A. J. (2009). Low flow controls on benthic 835 and hyporheic macroinvertebrate assemblages during supra-seasonal drought.

836 Hydrological Processes, 23, 2252-2263. doi:10.1002/hyp.7290

837 Suárez, M. L., Sánchez-Montoya, M. M., Gómez, R., Arce, M. I., del Campo, R., \& 838 Vidal-Abarca, M. R. (2017). Functional response of aquatic invertebrate communities 839 along two natural stress gradients (water salinity and flow intermittence) in 840 Mediterranean streams. Aquatic Sciences, 79, 1-12. doi:10.1007/s00027-016-04758412

842 Tachet, H., Bournaud, M., Richoux, P., \& Usseglio-Polatera, P. (2010). Invertébrés 843 d'eau douce: Systématique, Biologie, Écologie. CNRS Editions, Paris. 
844 Trivellone, V., Schoenenberger, N., Bellosi, B., Jermini, M., De Bello, F., Mitchell, E.

845 A., \& Moretti, M. (2014). Indicators for taxonomic and functional aspects of

846 biodiversity in the vineyard agroecosystem of Southern Switzerland. Biological

847 Conservation, 170, 103-109. doi:10.1016/j.biocon.2013.12.008

848 Tonkin, J.D., Bogan, M.T., Bonada, N., Rios-Touma, B. and Lytle, D.A. (2017).

849 Seasonality and predictability shape temporal species diversity. Ecology, 98, 1201-

850 1216. doi: 10.1002/ecy.1761.

851 UKTAG (2014). UKTAG river assessment method: benthic invertebrate fauna.

852 Invertebrates (general degradation): Whalley, Hawkes, Paisley \& Trigg (WHPT)

853 metric in River Invertebrate Classification Tool (RICT). Stirling: UK Technical

854 Advisory Group on the Water Framework Directive. Available at:

855 https://www.wfduk.org/resources/rivers-invertebrates-general-degradation

856 Vander Vorste, R. V., Corti, R., Sagouis, A., \& Datry, T. (2016). Invertebrate

857 communities in gravel-bed, braided rivers are highly resilient to flow intermittence.

858 Freshwater Science, 35, 164-177. doi:10.1086/683274

859 Van de Meutter, F., Stoks, R., \& De Meester, L. (2006). Lotic dispersal of lentic

860 macroinvertebrates. Ecography, 29, 223-230. doi: 10.1111/j.2006.0906-

861 7590.04483.x

862 Watts G., Battarbee R. W., Bloomfield J. P., Crossman J., Daccache A., Durance

863 I., ... Hannah D. M. (2015). Climate change and water in the UK - past changes and 864 future prospects. Progress in Physical Geography, 39, 6-28.

865 doi:10.1177/0309133314542957

866

Westwood, C. G., England, J., Dunbar, M. J., Holmes, N. T., Leeming, D. J. and

867

Hammond, D. (2017), An approach to setting ecological flow thresholds for southern

868 English chalk streams. Water and Environment Journal, 31, 528-536.

869 doi:10.1111/wej.12275

870 White, J. C., Hannah, D. M., House, A., Beatson, S. J. V., Martin, A., \& Wood, P. J.

871 (2017a). Macroinvertebrate responses to flow and stream temperature variability

872 across regulated and non-regulated rivers. Ecohydrology, 10, e1773.

873 doi:10.1002/eco.1773

874 White, J. C., Hill, M. J., Bickerton, M. A., \& Wood, P. J. (2017b). Macroinvertebrate

875 taxonomic and functional trait compositions within lotic habitats affected by river

876 restoration practices. Environmental Management, 60, 513-525. doi:

877 10.1007/s00267-017-0889-1

878 White, J. C., House, A., Punchard, N., Hannah, D. M., Wilding, N. A., \& Wood, P. J.

879 (2018). Macroinvertebrate community responses to hydrological controls and

880 groundwater abstraction effects across intermittent and perennial headwater 
881 streams. Science of the Total Environment, 610-611, 1514-1526.

882 doi:10.1016/j.scitotenv.2017.06.081

883 White, J. C., Krajenbrink, H. J., Hill, M. J., Hannah, D. M., House, A. \& Wood. P. J.

884 (2019) Habitat-specific invertebrate responses to hydrological variability,

885 anthropogenic flow alterations, and hydraulic conditions. Freshwater Biology, 64,

886 555-576. doi: 10.1111/fwb.13242

887 Wiberg-Larsen, P. (2008). Overall distributional patterns of European Trichoptera.

888 Ferrantia, 55, 143-155. doi: 10.1080/02705060.2003.9664005

889 Wilding, N. A., White, J. C., Chadd, R. P., House, A. \& Wood, P. J. (2018). The 890 influence of flow permanence and drying pattern on macroinvertebrate biomonitoring 891 tools used in the assessment of riverine ecosystems. Ecological Indicators, 85, 548892 555. doi: 10.1016/j.ecolind.2017.10.059

893 Williams, D. D. (1996). Environmental constraints in temporary fresh waters and their 894 consequences for the insect fauna. Journal of the North American Benthological 895 Society, 15, 634-650. doi:10.2307/1467813

896 Wood, P. J., Gunn, J., Smith, H., \& Abas-Kutty, A. (2005). Flow permanence and 897 macroinvertebrate community diversity within groundwater dominated headwater 898 streams and springs. Hydrobiologia, 545, 55-64. doi:10.1007/s10750-005-2213

899 Wood, P. J., \& Petts, G. E. (1999). The influence of drought on chalk stream 900 macroinvertebrates. Hydrological Processes, 13, 387-399. doi:10.1002/(SICI)1099901 1085(19990228)13:3<387::AID-HYP745>3.0.CO;2-R

902 Wright, J. F. (1992). Spatial and temporal occurrence of invertebrates in a chalk 903 stream, Berkshire, England. Hydrobiologia, 248, 11-30. doi:10.1007/BF00008882

904 Zuur, A.F., leno, E. N., \& Elphick, C. S. (2010). A protocol for data exploration to avoid 905 common statistical problems. Methods in Ecology and Evolution, 1(1), 3-14. 906 doi:10.1111/j.2041-210X.2009.00001.x

907

908

909 


\section{Tables}

Table 1. Summary of abiotic characteristics (mean values) for each of the six River Misbourne sites. Values represent the mean values recorded from three seasons (spring, summer and autumn) during a representative year (2005) as undertaken by the Environment Agency.

\begin{tabular}{|c|c|c|c|c|c|c|c|c|c|c|}
\hline Site & Longitude & $\begin{array}{c}\text { Distance } \\
\text { from source } \\
(\mathbf{k m})\end{array}$ & $\begin{array}{l}\text { Altitude } \\
\text { (m a.s.l.) }\end{array}$ & $\begin{array}{l}\text { Local } \\
\text { gradient } \\
\left(\mathrm{m} \mathrm{km}^{-1}\right)\end{array}$ & Width (m) & $\begin{array}{c}\text { Depth } \\
\text { (cm) }\end{array}$ & $\begin{array}{c}\text { Discharge } \\
\left(\mathrm{m}^{3} \mathrm{~s}^{-1}\right)\end{array}$ & $\begin{array}{l}\text { Flow } \\
\text { permanence } \\
\text { regime }\end{array}$ & $\begin{array}{c}\text { Mean number } \\
\text { of no flow } \\
\text { days per year }\end{array}$ & $\begin{array}{l}\text { Predictably of } \\
\text { dry phase } \\
\text { (Sd6) }\end{array}$ \\
\hline 1 & 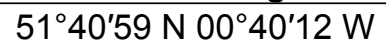 & 4.9 & 107 & 3.6 & 9.0 & 50.0 & 0.06 & Non-perennial & 80.68 & 0.73 \\
\hline 2 & $51^{\circ} 40^{\prime} 19 \mathrm{~N} 00^{\circ} 37^{\prime} 53 \mathrm{~W}$ & 7.8 & 98 & 2.8 & 4.0 & 25.0 & 0.14 & Perennial & 44.84 & 1.00 \\
\hline 3 & $51^{\circ} 38^{\prime} 54 \mathrm{~N} 00^{\circ} 34^{\prime} 49 \mathrm{~W}$ & 12.7 & 78 & 3.1 & 2.4 & 11.0 & 0.08 & Non-perennial & 111.52 & 0.38 \\
\hline 4 & 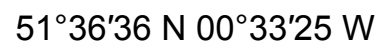 & 18.1 & 60 & 3.8 & 1.8 & 24.0 & 0.06 & Non-perennial & 201.88 & 0.41 \\
\hline 5 & $51^{\circ} 35^{\prime} 05 \mathrm{~N} 00^{\circ} 32^{\prime} 21 \mathrm{~W}$ & 21.6 & 49 & 4.5 & 3.9 & 20.7 & 0.18 & Perennial & 0.00 & 1.00 \\
\hline 6 & 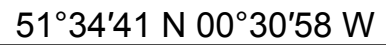 & 23.8 & 40 & 4.2 & 5.3 & 7.3 & 0.26 & Perennial & 0.00 & 1.00 \\
\hline
\end{tabular}

Table 2. Summary of linear mixed-effects models associated with flow

regime, season, site and the interaction of these factors. Significant results $(p<0.05)$ are emboldened.

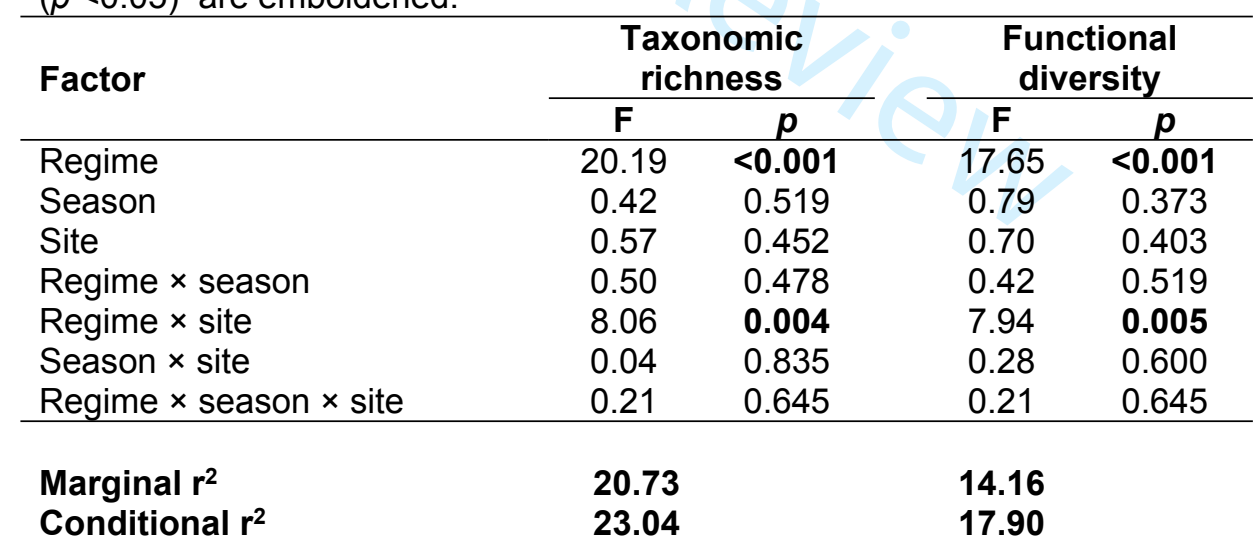


Table 3. Summary of PERMANOVA output assessing the relative importance of the different environmental controls on taxonomic and functional communities. Significant results $(p<0.05)$ are emboldened.

\begin{tabular}{lcccccccc}
\hline & \multicolumn{3}{c}{ Taxonomic } & & \multicolumn{3}{c}{ Functional } \\
\cline { 2 - 4 } \cline { 7 - 8 } Environmental factor & $\mathrm{F}$ & $\mathrm{r}^{2}$ & $p$ & & $\mathrm{~F}$ & $\mathrm{r}^{2}$ & $p$ \\
\hline Regime & 9.04 & 0.043 & $\mathbf{0 . 0 0 1}$ & & 11.96 & 0.057 & $\mathbf{0 . 0 0 1}$ \\
Season & 3.96 & 0.019 & $\mathbf{0 . 0 0 1}$ & & 3.98 & 0.019 & $\mathbf{0 . 0 0 1}$ \\
Site & 13.26 & 0.063 & $\mathbf{0 . 0 0 1}$ & & 3.42 & 0.016 & $\mathbf{0 . 0 0 2}$ \\
Regime $\times$ season & 1.35 & 0.006 & 0.169 & & 1.90 & 0.009 & 0.054 \\
Regime $\times$ site & 8.79 & 0.042 & $\mathbf{0 . 0 0 1}$ & & 13.86 & 0.066 & $\mathbf{0 . 0 0 1}$ \\
Season $\times$ site & 0.83 & 0.004 & 0.620 & & 0.58 & 0.002 & 0.805 \\
Regime $\times$ season $\times$ site & 0.85 & 0.004 & 0.612 & & 1.21 & 0.006 & 0.259 \\
\hline
\end{tabular}


911

912

913

914

915

916

917

918

919

Table 4. Summary of the top ten indicator taxa and traits for non-perennial and perennial flow regimes on global (spring and autumn) dataset.

\begin{tabular}{|c|c|c|c|c|c|}
\hline \multicolumn{3}{|c|}{ Taxonomic } & \multicolumn{3}{|l|}{ Functional } \\
\hline Taxa & Indicator value & $p$-value & Trait & Indicator value & $p$-value \\
\hline Non-perennial * & & & Non-perennial & & \\
\hline Lymnaeidae & 0.773 & 0.001 & Resistance form: cocoons & 0.780 & 0.001 \\
\hline Lumbricidae & 0.621 & 0.011 & Resistance form: housing against desiccation & 0.780 & 0.001 \\
\hline Physidae & 0.534 & 0.049 & Locomotion: surface swimmer & 0.770 & 0.001 \\
\hline Dytiscidae & 0.505 & 0.049 & Respiration: tegument & 0.737 & 0.001 \\
\hline Hydroptilidae & 0.505 & 0.003 & Locomotion: temporarily attached & 0.731 & 0.006 \\
\hline Crangonyctidae & 0.474 & 0.004 & Feeding group: scraper & 0.729 & 0.001 \\
\hline Perennial & & & $\begin{array}{l}\text { Reproduction strategy: clutches, cemented eggs } \\
\text { Aquatic stage: adult }\end{array}$ & $\begin{array}{l}0.729 \\
0.729\end{array}$ & $\begin{array}{l}0.001 \\
0.003\end{array}$ \\
\hline Elmidae & 0.811 & 0.001 & Food consumed: living microphytes & 0.728 & 0.004 \\
\hline Gammaridae & 0.772 & 0.001 & Voltinism: 1 & 0.721 & 0.002 \\
\hline Sericostomatidae & 0.728 & 0.001 & & & \\
\hline Baetidae & 0.697 & 0.039 & Perennial & & \\
\hline Ephemeridae & 0.690 & 0.001 & Voltinism: $<1$ & 0.776 & 0.001 \\
\hline Erpobdellidae & 0.684 & 0.001 & Maximal potential size: $>8 \mathrm{~cm}$ & 0.775 & 0.001 \\
\hline Hydrobiidae & 0.658 & 0.001 & Respiration: plastron & 0.768 & 0.001 \\
\hline Hydropsychidae & 0.653 & 0.002 & Locomotion: burrower & 0.761 & 0.001 \\
\hline Goeridae & 0.615 & 0.001 & Reproduction strategy: isolated eggs, cemented & 0.759 & 0.001 \\
\hline Glossiphoniidae & 0.609 & 0.030 & Feeding group: predator & 0.751 & 0.001 \\
\hline & & & Locomotion: permanently attached & 0.736 & 0.001 \\
\hline & & & Reproduction strategy: clutches, free & 0.736 & 0.032 \\
\hline & & & Respiration mode: gill & 0.735 & 0.001 \\
\hline & & & Dispersal strategy: aerial passive & 0.730 & 0.001 \\
\hline
\end{tabular}

* N.B. only six taxa were identified for this flow regime 
Table 5. Summary of multivariate dispersion distance by flow regime for taxonomic and functional communities on all (global), spring (March - May) and autumn (September November) samples.

\begin{tabular}{lccccccc}
\hline & \multicolumn{3}{c}{ Taxonomic } & & \multicolumn{3}{c}{ Functional } \\
\cline { 2 - 4 } \cline { 7 - 8 } & Global & Spring & Autumn & & Global & Spring & Autumn \\
\hline Perennial & 0.340 & 0.330 & 0.340 & & 0.075 & 0.074 & 0.074 \\
Non-perennial & 0.378 & 0.378 & 0.364 & & 0.105 & 0.111 & 0.096 \\
\hline
\end{tabular}

Table 6. Summary of ANOVA permutation dispersion tests between perennial and non-perennial sites for the global, spring and autumn datasets. Significant $(p<0.05)$ results are emboldened.

\begin{tabular}{lccc}
\hline & df & $\mathbf{F}$ & $\boldsymbol{p}$ \\
\hline Taxonomic & & & \\
Global & 1,178 & 14.447 & $\mathbf{< 0 . 0 0 1}$ \\
Spring & 1,88 & 10.368 & $\mathbf{0 . 0 0 2}$ \\
Autumn & 1,88 & 2.749 & 0.101 \\
Functional & & & \\
Global & 1,178 & 34.07 & $\mathbf{< 0 . 0 0 1}$ \\
Spring & 1,88 & 19.07 & $\mathbf{< 0 . 0 0 1}$ \\
Autumn & 1,88 & 14.771 & $\mathbf{< 0 . 0 0 1}$ \\
\hline
\end{tabular}

Table 7. Summary of significant variables influencing macroinvertebrate community composition as determined by redundancy analyses. \% W1 zero-flow days = \% of winter zero-flow days; \% S1 zero-flow days and \% S2 zero-flow days = \% of summer zero-flow days; mean W1= mean winter discharge; mean S1 and S2 = mean summer discharge. Two years of antecedent summer (April-September) and one year of winter (October-March) data were used respectively.

\begin{tabular}{lcclcc}
\hline Variable & $\mathbf{F}$ & $\boldsymbol{p}$ & Variable & $\mathbf{F}$ & $\boldsymbol{p}$ \\
\hline Taxonomic spring & & & Functional spring & & \\
\% S1 zero-flow days & 7.36 & 0.005 & \% S1 zero-flow days & 23.6 & 0.005 \\
Depth & 2.63 & 0.005 & Mean W1 & 2.30 & 0.040 \\
Width & 3.65 & 0.005 & Width & 2.08 & 0.040 \\
Mean W1 & 2.72 & 0.005 & & & \\
Gravel & 2.25 & 0.010 & & & \\
Mean S1 & 1.59 & 0.040 & & & \\
Taxonomic autumn & & & Functional autumn & 7.18 & 0.005 \\
Silt & 6.09 & 0.005 & Gravel & 4.50 & 0.005 \\
Pebble & 4.87 & 0.005 & \% S2 zero-flow days & 2.85 & 0.010 \\
\% W1 zero-flow days & 2.50 & 0.005 & Cobble & 2.13 & 0.040 \\
Depth & 2.27 & 0.010 & Width & 3.32 & 0.005 \\
Width & 2.50 & 0.005 & Depth & & \\
Mean S1 & 1.89 & 0.010 & & & \\
\hline
\end{tabular}




\section{Flow regime}

- Perennial

---- Non-perennial

Data collection points

(1) Macroinvertebrate sampling site

A Upper discharge gauging station (1989-2017)

V Lower discharge gauging station (1993-2017)

$\diamond$ Spot gauging station

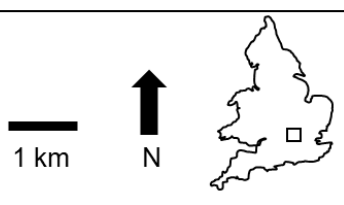

Figure 1.

55 

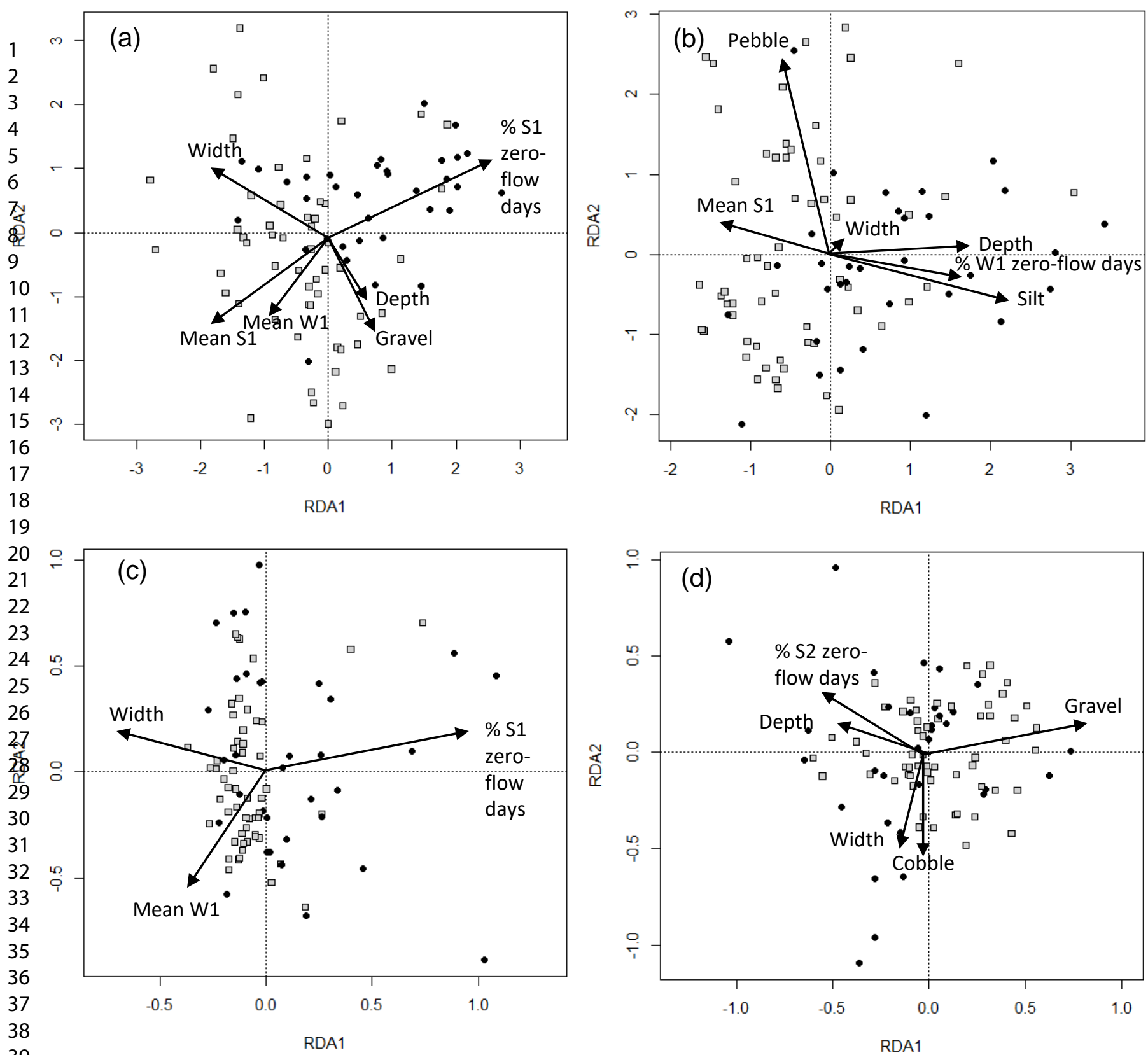

Figure 3. 
Supporting information for: Structural and functional responses of macroinvertebrate assemblages to long-term flow variability and drying at perennial and non-perennial sites

Kate L. Mathers, Rachel Stubbington, Judy England, David Leeming, Christian G. Westwood

Table S1. Trait categories and modalities used to characterise functional responses of River Misbourne macroinvertebrate communities (adapted from Tachet et al., 2010)

\begin{tabular}{|c|c|c|c|}
\hline Category & Modalities & Category & Trait \\
\hline \multirow[t]{7}{*}{ Maximal potential size } & $<0.25 \mathrm{~cm}$ & \multirow[t]{5}{*}{ Respiration } & Gill \\
\hline & $>0.25-0.5 \mathrm{~cm}$ & & Plastron \\
\hline & $>0.5-1 \mathrm{~cm}$ & & Spiracle \\
\hline & $>1-2 \mathrm{~cm}$ & & Hydrostatic vesicle \\
\hline & $>2-4 \mathrm{~cm}$ & & Tegument \\
\hline & $>4-8 \mathrm{~cm}$ & \multirow[t]{8}{*}{ Locomotion } & Flier \\
\hline & $>8 \mathrm{~cm}$ & & Surface swimmer \\
\hline Life cycle duration & $\leq 1$ year & & Full water swimmer \\
\hline & $>1$ year & & Crawler \\
\hline \multirow[t]{3}{*}{ Voltinism } & $<1$ & & Burrower \\
\hline & 1 & & Interstitial \\
\hline & $>1$ & & Temporarily attached \\
\hline \multirow[t]{4}{*}{ Aquatic stages } & Egg & & Permanently attached \\
\hline & Larva & \multirow[t]{8}{*}{ Feeding group } & Absorber \\
\hline & Nymph & & Deposit feeder \\
\hline & Adult & & Shredder \\
\hline \multirow[t]{7}{*}{ Reproduction strategy } & Ovoviviparity & & Scraper \\
\hline & Isolated, free eggs & & Filter-feeder \\
\hline & Isolated eggs, cemented & & Piercer \\
\hline & Clutches, cemented eggs & & Predator \\
\hline & Clutches, free & & Parasite \\
\hline & Clutches, in vegetation & \multirow[t]{9}{*}{ Food consumed } & Microorganisms \\
\hline & Asexual & & Detritus $<1 \mathrm{~mm}$ \\
\hline \multirow[t]{4}{*}{ Dispersal strategy } & Aquatic passive & & Dead plant $\geq 1 \mathrm{~mm}$ \\
\hline & Aquatic active & & Living microphytes \\
\hline & Aerial passive & & Living macrophytes \\
\hline & Aerial active & & Dead animal $\geq 1 \mathrm{~mm}$ \\
\hline \multirow[t]{4}{*}{ Resistance form } & Eggs / statoblasts & & Living microinvertebrates \\
\hline & Cocoons & & Living macroinvertebrates \\
\hline & Housings against desiccation & & Vertebrates \\
\hline & $\begin{array}{l}\text { Diapause / dormancy } \\
\text { None }\end{array}$ & & \\
\hline
\end{tabular}


Table S2. Summary of the River Misbourne linear regression analyses. $y=$ flow at the spot gauge site and $x=$ flow at the fixed gauging station.

\begin{tabular}{|c|c|c|c|}
\hline & Number of data points & Time period & $R^{2}$ value \\
\hline \multicolumn{4}{|c|}{ Site 1 - No regression applied. Direct gauge data used } \\
\hline Site 2: $y=1.199 x-0.040$ & 224 & October 1993 - February 2013 & 0.887 \\
\hline Site 3: $y=1.229 x-0.583$ & 230 & October 1993 - October 2010 & 0.583 \\
\hline Site 3: $y=1.033 x-0.050$ & 49 & November 2010- January 2016 & 0.901 \\
\hline Site 4: $y=0.672 x-0.092$ & 33 & October 1993 - May 2010 & 0.665 \\
\hline Site $4: y=2.455 x-0.247$ & 64 & November 2000 - January 2008 & 0.949 \\
\hline Site $4: y=1.156 x-0.163$ & 14 & February 2011 - June 2015 & 0.789 \\
\hline Site $4: y=1.652 x-0.144$ & 78 & December 2000 - June 2016 & 0.700 \\
\hline Site $5: y=0.740 x-0.026$ & 179 & February 1993 - April 2008 & 0.886 \\
\hline \multicolumn{4}{|c|}{ Site 6 - No regression applied. Direct gauge data used } \\
\hline
\end{tabular}

N.B. Sites 3 and 4 have multiple regressions reflecting changes in hydrological conditions; sites 1 and 6 are derived directly from the upper and lower gauging stations respectively. 
Table S3. Summary of the top ten indicator taxa and traits for each flow regime for spring samples (March - May).

\begin{tabular}{|c|c|c|c|c|c|}
\hline \multicolumn{3}{|c|}{ Taxonomic } & \multicolumn{3}{|l|}{ Functional } \\
\hline$\overline{\text { Taxa }}$ & Indicator value & $p$-value & $\overline{\text { Trait }}$ & Indicator value & $p$-value \\
\hline Non-perennial * & & & Non-perennial & & \\
\hline Lymnaeidae & 0.725 & 0.001 & Resistance form: cocoons & 0.792 & 0.001 \\
\hline Lumbricidae & 0.685 & 0.006 & Resistance form: housing against desiccation & 0.792 & 0.001 \\
\hline \multirow[t]{2}{*}{ Dytiscidae } & 0.604 & 0.002 & Locomotion: surface swimmer & 0.766 & 0.011 \\
\hline & & & Locomotion: temporarily attached & 0.748 & 0.003 \\
\hline Perennial & & & Respiration: tegument & 0.740 & 0.001 \\
\hline Elmidae & 0.796 & 0.001 & Reproduction strategy: clutches, cemented eggs & 0.736 & 0.002 \\
\hline Gammaridae & 0.781 & 0.001 & Aquatic stage: nymph & 0.734 & 0.045 \\
\hline Sericostomatidae & 0.738 & 0.001 & Feeding group: scraper & 0.732 & 0.001 \\
\hline Hydropsychidae & 0.714 & 0.002 & Food consumed: living microphytes & 0.726 & 0.009 \\
\hline Erpobdellidae & 0.697 & 0.002 & Voltinism: 1 & 0.717 & 0.009 \\
\hline Hydracarina & 0.692 & 0.006 & & & \\
\hline Ephemeridae & 0.689 & 0.002 & Perennial & & \\
\hline Hydrobiidae & 0.669 & 0.001 & Maximal potential size: $>8 \mathrm{~cm}$ & 0.776 & 0.001 \\
\hline Caenidae & 0.657 & 0.043 & Reproduction strategy: isolated eggs, cemented & 0.775 & 0.001 \\
\hline \multirow[t]{8}{*}{ Leptoceridae } & 0.651 & 0.022 & Voltinism: $<1$ & 0.768 & 0.001 \\
\hline & & & Food consumed: microorganisms & 0.761 & 0.001 \\
\hline & & & Locomotion: permanently attached & 0.759 & 0.001 \\
\hline & & & Locomotion: burrower & 0.751 & 0.001 \\
\hline & & & Feeding group: predator & 0.736 & 0.001 \\
\hline & & & Respiration: plastron & 0.736 & 0.032 \\
\hline & & & Respiration mode: gill & 0.735 & 0.001 \\
\hline & & & Maximal potential size: $>2-4 \mathrm{~cm}$ & 0.730 & 0.001 \\
\hline
\end{tabular}

* N.B. only three taxa were identified for this flow permanence regime 
Table S4. Summary of the top ten indicator taxa and traits for each flow regime for autumn samples (September - November)

\begin{tabular}{|c|c|c|c|c|c|}
\hline \multicolumn{3}{|c|}{ Taxonomic } & \multicolumn{3}{|l|}{ Functional } \\
\hline Taxa & Indicator value & $p$-value & Trait & Indicator value & $p$-value \\
\hline Non-perennial * & & & Non-perennial & & \\
\hline Lymnaeidae & 0.820 & 0.001 & Locomotion: surface swimmer & 0.773 & 0.009 \\
\hline Hydroptilidae & 0.557 & 0.005 & Resistance form: cocoons & 0.764 & 0.001 \\
\hline Corixidae & 0.482 & 0.039 & Resistance form: housing against desiccation & 0.764 & 0.001 \\
\hline \multirow[t]{2}{*}{ Crangonyctidae } & 0.479 & 0.034 & Aquatic stage: adult & 0.735 & 0.004 \\
\hline & & & Respiration: tegument & 0.734 & 0.001 \\
\hline Perennial & & & Feeding group: scraper & 0.726 & 0.015 \\
\hline Elmidae & 0.822 & 0.001 & Maximal potential size: $>1-2 \mathrm{~cm}$ & 0.726 & 0.008 \\
\hline Gammaridae & 0.762 & 0.002 & Dispersal strategy: aquatic passive & 0.722 & 0.001 \\
\hline Sericostomatidae & 0.718 & 0.001 & Voltinism: 1 & 0.722 & 0.05 \\
\hline Ephemeridae & 0.687 & 0.007 & Maximal potential size: $<0.25 \mathrm{~cm}$ & 0.641 & 0.006 \\
\hline Erpobdellidae & 0.669 & 0.001 & & & \\
\hline Simuliidae & 0.648 & 0.016 & Perennial & & \\
\hline Hydrobiidae & 0.647 & 0.002 & Respiration: plastron & 0.776 & 0.001 \\
\hline Goeridae & 0.632 & 0.002 & Voltinism: $<1$ & 0.775 & 0.001 \\
\hline Odontoceridae & 0.582 & 0.002 & Maximal potential size: $>8 \mathrm{~cm}$ & 0.768 & 0.001 \\
\hline \multirow[t]{7}{*}{ Psychomyiidae } & 0.537 & 0.005 & Locomotion: burrower & 0.761 & 0.001 \\
\hline & & & Reproduction strategy: clutches, free & 0.759 & 0.001 \\
\hline & & & Feeding group: predator & 0.751 & 0.001 \\
\hline & & & Maximal potential size: $>0.25-0.5 \mathrm{~cm}$ & 0.736 & 0.001 \\
\hline & & & Locomotion: flier & 0.736 & 0.032 \\
\hline & & & Dispersal strategy: aerial passive & 0.735 & 0.001 \\
\hline & & & Reproduction strategy: isolated eggs, cemented & 0.730 & 0.001 \\
\hline
\end{tabular}

${ }^{*}$ N.B. only four taxa were identified for this flow regime 
Table S5. Summary of the model outputs from redundancy analyses

\begin{tabular}{|c|c|c|c|c|c|}
\hline \multirow{2}{*}{ Dataset } & \multicolumn{3}{|c|}{$\begin{array}{l}\text { Principal component (\% } \\
\text { variance explained) }\end{array}$} & \multirow[t]{2}{*}{$\mathbf{F}$} & \multirow[t]{2}{*}{$p$} \\
\hline & 1 & 2 & Total & & \\
\hline Taxonomic spring & 9.08 & 5.05 & 14.13 & 2.28 & 0.001 \\
\hline Taxonomic autumn & 8.20 & 5.66 & 13.86 & 2.46 & 0.001 \\
\hline Functional spring & 23.12 & 4.65 & 27.77 & 3.34 & 0.001 \\
\hline Functional autumn & 12.1 & 6.82 & 18.92 & 2.82 & 0.001 \\
\hline
\end{tabular}

